\title{
Retrospective review of two-port thoracoscopic (VATS) wedge bullectomy and lung wedge biopsy
}

\author{
Jimmy Bejjani*, Guillaume Couture, Juan-Francisco Asenjo, Marco Sirois, \\ Chantal Sirois, Christian Sirois
}

\begin{abstract}
Background: Video-assisted thoracoscopic surgery (VATS) involving wedge resection of bulla and lung biopsy can be done by two or three-port incisions. Controversy exists as to which approach is superior. We communicate our experience with two-port VATS for these procedures. Methods: We retrospectively analyzed the charts of all patients who underwent a VATS procedure by two-port incisions from July 2001 to July 2007 by two thoracic surgeons (S.C., S.C.) We included in the study all patients who underwent wedge resections for primary or secondary spontaneous pneumothorax and biopsies for pulmonary infiltrates and small nodules. Results: A total of 319 patients' charts were examined, and 217 of whom had undergone two-port incisions fitted in the inclusion criteria. There were $136(65.7 \%)$ males and $81(37.3 \%)$ females with a mean age of 47 years. Pneumothorax was the main diagnosis for $98(45 \%)$ patients, followed by pulmonary infiltrates for 69 (32\%) patients and lung nodules for $50(23 \%)$ patients. The mean operative time and the number of post-op days for chest tube removal and to discharge home in each group have also been recorded. There were few post-operative complications, such as $11(5 \%)$ cases of persistent air leak, $11(5 \%)$ cases of transient fever of unknown origin, $3(1.4 \%)$ cases of pneumonia, $3(1.4 \%)$ cases of bleeding within, one reoperated, and $1(0.46 \%)$ case of $\mathrm{C}$. difficile colitis. The 30-day mortality was $0 \%$. Conclusion: The thoracoscopic (VATS) wedge biopsy via two-port incisions is a safe operation for patients presenting with pneumothorax or requiring a lung biopsy. A two-port approach seems to be a reasonable alternative to three-port incision procedures for these types of diagnosis, regarding post-operative pain and cosmetic benefits particularly for young patients.
\end{abstract}

KEYWORDS: VATS, pneumothorax, bullectomy, thoracoscopy, pleurodesis, pulmonary nodule, pulmonary infiltrates, lung neoplasms.

\section{INTRODUCTION}

Lung cancer incidence was 73,6/100,000 in 2004 in the United States (1), and spontaneous pneumothorax are more rare. Between 1991 and 1995, the rate of admissions to UK hospitals for both primary and secondary spontaneous pneumothorax was 16.7 per 100,000 men per year and 5.8 per 10,.000 women per year (2). One diagnostic and therapeutic alternative to thoracotomy is video-assisted thoracoscopic surgery

*To whom correspondence should be addressed:

Jimmy Bejjani

730, Montpellier, apt 302

Montreal, QC, H4L 5B3

Canada

Email: Jimmy.Bejjani@USherbrooke.ca
(VATS), allowing wedge bullectomy and lung wedge biopsy while reducing pain by smaller incisions and leading to shorter hospital stay. VATS can be performed by three, two and even one-port incisions. Controversy exists as to which approach is superior $(3,4)$. At our institution, three surgeons use either two-port or threeport procedure VATS but otherwise the same technic. They do not use one-port. We have reviewed our experience with two-port VATS over the last 6 years to determine wether this approach can be regarded as safe.

\section{PATIENTS AND METHODS \\ Patients}

The charts of all patients who underwent a thoracoscopic procedure by two-port incisions from July 2001 to July 2007 by two thoracic surgeons were 
reviewed. We included in the study all patients who underwent wedge resections for spontaneous pneumothorax and wedge biopsies for pulmonary infiltrates and small nodules $(<1.5 \mathrm{~cm})$. The exclusion criteria were high pre-operative $\mathrm{O} 2$ requirement (FiO2>0.5), large nodules (greater than $1.5 \mathrm{~cm}$ diameter), diffuse severe emphysema, giant bulla, and those who were converted to open surgery for any reason.

\section{Data collection}

Retrospective data collection includes comorbidities, surgical treatment received, duration of surgery, duration of chest tubes, hospital length of stay (LOS), post-operative complications and analgesia.

\section{Surgical procedure}

All patients were operated using the same technique. Under general anesthesia with double lumen intubation, the patient was placed on the lateral decubitus position to expose the left or right chest. A small $2 \mathrm{~cm}$ transverse skin incision was performed on the lateral and lower aspect of the chest. A tunneled dissection was made superiorly for subsequent chest tubes. The 8th or 9th intercostal space was opened. The lung was deflated. A second thoracoscopic port incision was performed more superiorly and anteriorly or posteriorly.

Following that, a 10-mm, 0' thoracoscope (Karl Storz) with a working channel was introduced into the pleural cavity through the first incision. Careful inspection of the pleural space was performed.

For bullectomy and pleurectomy or pleurodesis, the apex of the upper lobe, having blebs, was grasped through the working port of the scope and an Endo GIA-45 stapler ( $3.5 \mathrm{~mm}$ green cartridge Ethicon $\left.{ }^{\circledR}\right)$ was used through the second port. The upper segment of the lower lobe was carefully inspected and blebs were resected using the same technic.

\begin{tabular}{|l|c|c|c|c|c|c|}
\hline \multicolumn{1}{|c|}{ Diagnosis } & $\mathbf{N}$ & $\mathbf{\%}$ & $\delta$ & $\circ$ & $\begin{array}{c}\text { Mean } \\
\text { age (yr) }\end{array}$ & $\begin{array}{c}\text { Range } \\
(\mathbf{y r})\end{array}$ \\
\hline $\begin{array}{l}\text { Primary } \\
\text { spontaneous } \\
\text { pneumothorax }\end{array}$ & 81 & 37.3 & 66 & 15 & 29.3 & $17-83$ \\
\hline $\begin{array}{l}\text { Secondary } \\
\text { spontaneous } \\
\text { pneumothorax }\end{array}$ & 18 & 8.3 & 14 & 4 & 52.7 & $14-79$ \\
\hline $\begin{array}{l}\text { Pulmonary } \\
\text { infiltrates }\end{array}$ & 68 & 31.3 & 33 & 35 & 64.4 & $18-83$ \\
\hline $\begin{array}{l}\text { Pulmonary } \\
\text { nodules }\end{array}$ & 50 & 23 & 23 & 27 & 50.4 & $23-81$ \\
\hline
\end{tabular}

Table 1: Demographic data.
Regarding lung wedge biopsy for nodules or infiltrates, limited small wedge resections were performed using an endograsper and an endoGIA-45 $4.8 \mathrm{~mm}$ stapler. The wedge resections for biopsy were performed in different areas of the lung to obtain a good sampling.

Combined apical pleurectomy and mechanical pleural abrasion was performed for pleurodesis, on the anterior, lateral, and posterior aspects of the chest wall. For some elderly patients with chronic obstructive pulmonary disease, following the mechanical abrasion, talc poudrage was used to achieve optimal pleurodesis. Following irrigation and suction with normal saline, a 32 French chest tube was placed posteriorly to the lung up into the apex through the camera port. The lung was reinflated. All the incisions were closed using 0 Vicryl sutures stitched on the subcutaneous tissue and Monocryl 4-0 subcuticular on the skin. Intercostal block with bupivacaine 0.25 with epinephrine was done in the intercostal space where the trocar and the chest tube have been placed.

\section{RESULTS}

We reviewed the charts of 319 patients and a total of 217 patients had undergone two-ports incisions and fit in the inclusion criteria; all remaining cases corresponded to any of the exclusion criteria. There were $136(65.7 \%)$ males and $81(37.3 \%)$ females with a mean age of 47 years (range 14-84).

General demographic data are shown in table 1.

The operative time, LOS, chest tube requirement time duration are summarized in table 2 .

We noticed that $16 \%$ of primary spontaneous pneumothorax (PSP) cases showed postoperative complications, $19 \%$ for secondary spontaneous pneumothorax (SSP), 14\% for pulmonary nodules and $12 \%$ for pulmonary infiltrate.

The most common postoperative complications were

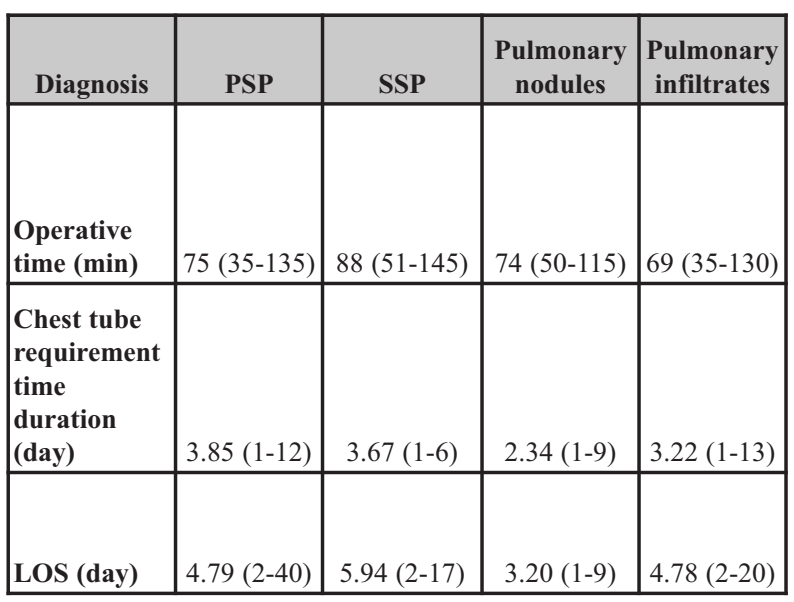

Table 2: Operative time, chest tubes duration and LOS. 
$11(5 \%)$ cases of persistent air leak, $11(5 \%)$ cases of transient fever peak of unknown origin, $3(1.4 \%)$ cases of pneumonia, 3 cases (1.4\%) of postoperative bleeding, and $1(0.46 \%)$ case of $\mathrm{C}$. difficile colitis which has resolved. There were no cases of wound/cellulitis, empyema, arrhythmia or cardio-vascular event. Only three cases of primary spontaneous pneumothorax needed a reoperation for bleeding, persistant air leak and a recurrency. The 30 -day mortality was $0 \%$.

Within the 98 patients operated for pneumothorax, 82 $(83.7 \%)$ underwent pleurodesis by mechanical abrasion, $6(6.1 \%)$ by talc poudrage, and $10(10.2 \%)$ received no pleurodesis. Within the 69 patients operated for infiltrates, 1 (1.4\%) underwent pleurodesis by mechanical abrasion, 3 (4.3\%) by talc poudrage and 65 (94\%) received no pleurodesis (figures 1 and 2).

\section{DISCUSSION}

VATS is known for being both an effective diagnosis and therapeutic tool employing minimally invasive techniques. It became involved in the diagnosis of idiopathic interstitial lung disease (5), and the staging of lung nodules (6) while allowing a simultaneous assessment of the pleura. It also facilitates the treatment of pneumothorax by wedge bullectomy and pleurodesis. For primary spontaneous pneumothorax, it has even been demonstrated effective and safe for the first episode (7).

Our cohort data suggests that the average operative time is proportional to the number of postoperative days to remove chest tubes and discharge home if no postoperative adverse event occurs. This constatation excludes the cases involving pulmonary infiltrates for which the longer length of stay is due to the preoperative disease.

Compared to other VATS studies for spontaneous pneumothorax and indeterminate interstitial lung disease, our data shows good results regarding operative time, chest-tube drainage, and postoperative hospital stay.

For mean operative time, studies state values as $57 \pm 19$ minutes (8), 67.9 \pm 16.7 minutes (5), and 129 minutes (9). For pleural drainage, studies show mean duration as 1.4 days (range 1-7) (10), 4.1 days (9), $5.8 \pm 1.2$ days (2), and $6.0 \pm 4.7$ days (5). For postoperative hospitalization, values were published for 2.4 days (10), 4 days $(9,11)$, 5 days (12), $7.7 \pm 1.6$ days (8), $7.9 \pm 4.7$ days (5), and 9.5 days (9).

Compared with previous studies in terms of postoperative mortality and morbidity, our sample of patients who underwent two-ports surgery for VATS had very good results.

Regarding 30-day mortality, studies often depicts no cases $(5,7-9,12-14)$ or rates as low as $0.5 \%(15), 0.8 \%$
(16), $1.3 \%$ (17) and 3.6\% (18). This last increased rate was seen for secondary spontaneous pneumothorax, due to diagnosed pulmonary pathologies as emphysema. Higher rates are present for postoperative complications, for which increasing factors include extreme age range and preoperative comorbidities. Studies depict morbidity of $9.6 \%$ for nodules (15), $1.7 \%$ (13), $25.4 \%$ (17), and $27.4 \%$ (8) for primary spontaneous pneumothorax, and $25 \%$ (13) and $76.9 \%$ (17) for secondary spontaneous pneumothorax. In previous reviews, persistant air leak was seen for $10 \%$ to $11.5 \%$ of procedures $(9,17)$, pneumonia in up to $6.7 \%$ (17), bleeding in 1.6\% (19). Those rates are equivalent or higher to ours. Moreover, others describe arrythmia (17), empyema (17), and wound infection (13) that didn't occur in our cohort.

To minimize these complications, authors recommend a close monitoring in the post-operative care unit and on the ward. Vital signs, chest tubes drainage and incision wounds should be checked by the surgical team in morning rounds, and twice a day by nurses. Moreover, chest radiographs and complete blood count may be of particular interest if patients are symptomatic. Prevention of C. difficile infection is also important with a judicious use of antibiotics and isolation when necessary.

Interestingly, during the post-operative days, patients operated for lung infiltrates consumed more morphine $(65.3 \mathrm{mg})$ than patients who underwent the surgery for lung nodules and pneumothorax (48.4 mg and $42.1 \mathrm{mg}$, respectively).

We noticed that the practice of pleurodesis did not significantly increase the use of narcotics, despite the earlier notion that pleurodesis increase pain in an important way. Post-operative morphine administration levels in pneumothorax cases whom surgery included mechanical abrasion illustrate an average difference of less than $10 \mathrm{mg}$ in post-operative day 1 and 2 (figure 1). This value spread is negligeable. A study also suggested that additionnal mechanical pleurodesis has no disadvantages versus bullectomy alone in terms of worsening post-operative chest pain or pulmonary function (20).

Chemical talc pleurodesis appears to decrease the need for post-operative morphine. In our cohort, postoperative morphine administration levels in cases of pulmonary infiltrates were much greater for patients receiving no pleurodesis than for those receiving chemical talc pleurodesis. However, this included only 3 patients and is therefore highly suseptible to hazard (figures 1 and 2).

\section{CONCLUSION}

We conclude that thoracoscopy (VATS) via two-port 
incisions is a safe and efficient procedure for patients presenting a pneumothorax or requiring a lung biopsy. Our complication rate is similar or lower to the rates of three-port thoracoscopy. This technique is arguably superior to three-port incisions based on the finding that it may decrease the postoperative pain and neuralgia risks, and presents obvious cosmetic benefits particularly for young patients. A comparative study with three-port incisions is warranted to elucidate this controversy.

\section{ACKNOWLEGMENT}

This review project was partially funded by the Dr. Clarke K. McLeod Memorial Scholarship Fund in 2007.

\section{REFERENCES}

1. Cancer Facts and Figures, American Cancer Society, 2008.

2. Gupta D, Hansell A, Nichols T, et al. Epidemiology of pneumothorax in England. Thorax. 2000; 55: 666-71.

3. Salati M, Brunelli A, Xiumè F, et al. Uniportal video-assisted thoracic surgery for primary spontaneous pneumothorax: clinical and economic analysis in comparison to the traditional approach. Interact Cardiovasc Thorac Surg. 2008; 7: 63-6.

4. Tagaya N, Kasama K, Suzuki N et al. Video-assisted bullectomy using needlescopic instruments for spontaneous pneumothorax. Surg Endosc. 2003;17: 1486-7.

5. Zaraca F, Ebner H. Video-assisted thoracoscopic biopsy in the diagnosis of idiopathic interstitial lung disease. Chir Ital. 2006; 58: 569-76.

6. Murasugi M, Onuki T, Ikeda T, et al. The role of video-assisted thoracoscopic surgery in the diagnosis of the small peripheral pulmonary nodule. Surg Endosc. 2001; 15: 734-6.

7. Chou SH, Cheng YJ, Kao EL. Is video-assisted thoracic surgery indicated in the first episode primary spontaneous pneumothorax? Interact Cardiovasc Thorac Surg. 2003;2: 552-4.

8. Lang-Lazdunski L, Chapuis O, Bonnet PM, et al. Videothoracoscopic bleb excision and pleural abrasion for the treatment of primary spontaneous pneumothorax: long-term results. Ann Thorac Surg 2003; 75: 960-5.
9. Lee JM, Lee YC, Huang CJ, et al. The role of video-assisted thoracic surgery in the diagnosis and treatment of indeterminate pulmonary lesion. Int Surg 1996; 81:327-9.

10. Czerny M, Salat A, Fleck $\mathrm{T}$, et al. Lung wedge resection improves outcome in stage I primary spontaneous pneumothorax. Ann Thorac Surg. 2004; 77:1802-5.

11. Ayed AK, Al-Shawaf E. A survey of 150 video-assisted thoracoscopic procedures in Kuwait. Med Princ Pract. 2004 May-Jun;13(3):159-63

12. Celik M, Halezeroglu S, Senol C, et al. Video-assisted thoracoscopic surgery: experience with 341 cases. Eur J Cardiothorac Surg. 1998; 14: 113-6.

13. Passlick B, Born C, Haussinger K, et al. Efficiency of videoassisted thoracic surgery for primary and secondary spontaneous pneumothorax. Ann Thorac Surg 1998; 65: 324-7.

14. Inderbitzi RG, Leiser A, Furrer M, et al. Three years' experience in video-assisted thoracic surgery (VATS) for spontaneous pneumothorax. J Thorac Cardiovasc Surg. 1994;107:1410-5.

15. Jiménez MF; Spanish Video-Assisted Thoracic Surgery Study Group. Prospective study on video-assisted thoracoscopic surgery in the resection of pulmonary nodules: 209 cases from the Spanish Video-Assisted Thoracic Surgery Study Group. Eur J Cardiothorac Surg. 2001; 19: 562-5.

16. Ingolfsson I, Gyllstedt E, Lillo-Gil R, et al. Reoperations are common following VATS for spontaneous pneumothorax: study of risk factors. Interact Cardiovasc Thorac Surg. 2006; 5: 602-7.

17. de Vos B, Hendriks J, Van Schil P, Van Hee R, et al. Long-term results after video-assisted thoracic surgery for spontaneous pneumothorax. Acta Chir Belg 2002; 102: 439-44.

18. Waller DA. Video-assisted thoracoscopic surgery for spontaneous pneumothorax-a 7-year learning experience. Ann R Coll Surg Engl 1999; 81: 387-92.

19. Chen JS, Hsu HH, Kuo SW, et al. Needlescopic versus conventional video-assisted thoracic surgery for primary spontaneous pneumothorax: a comparative study Ann Thorac Surg. 2003;75:1080-5

20. Horio H, Nomori H, Kobayashi R, Naruke T, Suemasu K. Impact of additional pleurodesis in video-assisted thoracoscopic bullectomy for primary spontaneous pneumothorax. Surg Endosc 2002; 16: 630-4.

Jimmy Bejjani (MD 2010) is studying medicine at the University of Sherbrooke, QC. He's involved in studies over surgical fields since 2005 .

Guillaume Couture graduated from physiology in 2007 at McGill University.

Juan-Francisco Asenjo, MD FRCP, is a professor in anesthesia and pain management at the McGill University Health Centre. He achieved a fellowhip in cardiac anesthesia and research, and a second fellowship in pain management.

Marco Sirois, MD FRCSC, is a professor in thoracic surgery at the Sherbrooke University Health Centre. He received a fellowship in traumatology, and a second fellowship in cardiothoracic surgery.

Christian Sirois, MD FRCSC, is a professor in thoracic surgery at the McGill University Health Surgery. He received a second residency in thoracic surgery, and a third residency in cardiothoracic surgery. 